IZA DP No. 9051

Peer Effects on Obesity in a Sample of European Children

Wencke Gwozdz Alfonso Sousa-Poza Lucia A. Reisch Karin Bammann Gabriele Eiben Yiannis Kourides
Eva Kovács Fabio Lauria Kenn Konstabel Alba M. Santaliestra-Pasias Krishna Vyncke Iris Pigeot

May 2015 


\section{Peer Effects on Obesity \\ in a Sample of European Children}

\author{
Wencke Gwozdz \\ Copenhagen Business School
}

Alfonso Sousa-Poza

University of Hohenheim and IZA

Lucia A. Reisch

Copenhagen Business School

Karin Bammann

University of Bremen

Gabriele Eiben

University of Gothenburg

Yiannis Kourides

Research and Education Institute of Child Health, Cyprus

\author{
Eva Kovács \\ University of Pécs
}

Fabio Lauria

National Research Council, Italy

Kenn Konstabel

University of Tartu

Alba M. Santaliestra-Pasias

University of Zaragoza

Krishna Vyncke

Ghent University

Iris Pigeot

BIPS, University of Bremen

Discussion Paper No. 9051

May 2015

IZA

P.O. Box 7240

53072 Bonn

Germany

Phone: +49-228-3894-0

Fax: +49-228-3894-180

E-mail: iza@iza.org

Any opinions expressed here are those of the author(s) and not those of IZA. Research published in this series may include views on policy, but the institute itself takes no institutional policy positions. The IZA research network is committed to the IZA Guiding Principles of Research Integrity.

The Institute for the Study of Labor (IZA) in Bonn is a local and virtual international research center and a place of communication between science, politics and business. IZA is an independent nonprofit organization supported by Deutsche Post Foundation. The center is associated with the University of Bonn and offers a stimulating research environment through its international network, workshops and conferences, data service, project support, research visits and doctoral program. IZA engages in (i) original and internationally competitive research in all fields of labor economics, (ii) development of policy concepts, and (iii) dissemination of research results and concepts to the interested public.

IZA Discussion Papers often represent preliminary work and are circulated to encourage discussion. Citation of such a paper should account for its provisional character. A revised version may be available directly from the author. 
IZA Discussion Paper No. 9051

May 2015

\section{ABSTRACT}

\section{Peer Effects on Obesity in a Sample of European Children ${ }^{*}$}

This study analyzes peer effects on childhood obesity using data from the first two waves of the IDEFICS study, which applies several anthropometric and other measures of fatness to approximately 14,000 children aged two to nine participating in both waves in 16 regions of eight European countries. Peers are defined as same-sex children in the same school and age group. The results show that peer effects do exist in this European sample but that they differ among both regions and different fatness measures. Peer effects are larger in Spain, Italy, and Cyprus - the more collectivist regions in our sample - while waist circumference generally gives rise to larger peer effects than BMI. We also provide evidence that parental misperceptions of their own children's weight goes hand in hand with fatter peer groups, supporting the notion that in making such assessments, parents compare their children's weight with that of friends and schoolmates.

JEL Classification: I12, J13, J22

Keywords: peer effects, children, obesity, Europe

Corresponding author:

Alfonso Sousa-Poza

University of Hohenheim

Institute for Health Care \& Public Management

Fruwirthstr. 48

70599 Stuttgart

Germany

E-mail: alfonso.sousa-poza@uni-hohenheim.de 


\section{Peer Effects on Obesity in a Sample of European Children}

\section{Introduction}

Child obesity is a major public health concern in Europe. According to self-reported data on height and weight gathered by the 2005-2006 Health Behaviour in School-aged Children (HBSC) survey from 11-year-olds in 26 EU countries, up to 30\% of boys and 25\% of girls could be considered overweight or obese (EC, 2010). In some European countries, the prevalence of overweight among children of primary school age is alarming: $35.9 \%$ of eightto nine-year-olds in Italy, 31.5\% of seven- to nine-year-olds in Portugal, and 30.6\% of six- to ten-year-olds in the Czech Republic are considered overweight or obese. Even in European countries like Sweden that have the lowest levels of child obesity, the prevalence is still high, with approximately every fifth child aged eight years being overweight or obese (WHO, 2009). In addition, although the empirical evidence is limited, there are strong indications that child obesity levels are rising (WHO, 2009). Most worrying is that despite efforts by international organizations and national governments to promote awareness of the problem and develop preventive measures, the prevalence continues to increase (WHO, 2009).

Many factors may play an important role in explaining child obesity, including parental influence, food prices, access to fast food, environment, opportunities for physical activities, school nutrition policies, and advertising. Yet such "root causes" cannot always explain excess variance within regions or racial groups. One additional explanation for the persistent increase in obesity levels - and one that has received considerable attention in recent years is the effect of peer groups. In addition to the ample documentation that social norms affect a range of health behaviors, including smoking (e.g., Mercken et al., 2012) and alcohol consumption (e.g. Balsa et al., 2011), there is increasing evidence that social norms and peer groups significantly affect obesity weight control behavior among both adolescents and adults (e.g., Christakis and Fowler, 2007; Hammond, 2010; Wal, 2012). For example, Christakis and Fowler's (2007) seminal longitudinal analysis of the Framingham Heart Study shows that an individual's chances of becoming obese increase by $57 \%$ if he or she has a friend who becomes obese in a given interval. Numerous subsequent studies also support the notion that social norms and networks affect individual obesity (Cohen-Cole and Fletcher, 2008; Renna et al., 2008; Trogdon et al., 2008; Christakis and Fowler, 2007; Halliday and Kwak, 2009; Valente et al., 2009; Larson et al., 2013; Yang and Huang, 2013; Blanchflower et al., 2009; Leatherdale and Papadakis, 2011; Mora and Gil, 2013; Loh and Li, 2013). 
Nevertheless, although several extant studies examine peer effects on obesity among adults and adolescents, we are aware of only one published study that explores peer effects on childhood obesity (Asirvatham et al., 2014). ${ }^{1}$ Yet knowing whether such effects exist among children is particularly important not only because children who are overweight before puberty will be overweight in early adulthood but healthy eating behaviors and diets take shape early in life and persist into adulthood (Schwartz et al., 2011). Hence, in the presence of peer effects among children, the oft-cited "social multiplier effect" (Christakis and Fowler, 2007) associated with policies aimed at combatting obesity may be quite effective and highly beneficial. ${ }^{2}$ Finally, a large body of psychological research provides "ample evidence that peers can contribute to the amplification of problem behavior and distress from early childhood through late adolescence” (Dishion and Tipsord, 2011, p. 203).

The focus of our study, therefore, is to assess peer effects among children in a selection of European countries. To do so, we draw on the unique IDEFICS study ("Identification and prevention of Dietary and lifestyle induced health EFfects In Children and infantS”) dataset, which covers approximately 14,000 children aged two to nine years participating in both the baseline and the follow-up survey in 16 regions of eight European countries. Our analysis makes the following contributions to the literature on peer effects and obesity: first, because a lack of appropriate data has seemingly prevented previous analyzes of peer effects on obesity in early and middle childhood (Cunningham et al., 2012), ${ }^{3}$ our study serves as a primer in this regard. Second, our analysis is one of very few that explores peer effects on obesity in Europe (one exception being Mora and Gil, 2013). Third, our dataset allows us to analyze several measures of fatness, some arguably better suited to measuring body fat than the Body Mass Index (BMI) (Burkhauser and Cawley, 2008; Gallagher et al., 1996; McCarthy et al., 2006; Romero-Corral et al., 2006; Wellens et al., 1996; Yusuf et al., 2005). Finally, by including data on weight perceptions, our study is able to determine an association between peers and social norms, thereby shedding light on the mechanisms through which peer influences may occur.

1 In Asirvatham et al. (2014) the effect of older peers on younger ones is analyzed. Their 2013 unpublished study (Asirvatham et al., 2013) is more akin to ours as it analyzed the effects of same-aged peers. Another recent but as yet unpublished paper on peer effects on childhood obesity is Nie et al. (2014).

2 In Trogdon and Allaire (2014) an agent-based model of weight choice and peer selection is developed that simulates the effect of peer selection on social multipliers for weight loss interventions.

3 As Cunningham et al. (2012) explain in their literature review: "We did not restrict inclusion criteria based on age, but, because few datasets are designed to permit research on friendship influence, many studies relied on one of the few datasets that does so, the National Longitudinal Study of Adolescent Health [...], and so focused on adolescence and early adulthood. Few studies have focused on adults [...] and none on early or middle childhood" (p. 1181). 
The remainder of the paper proceeds as follows: section 2 reviews the relevant research on the topic, section 3 describes our data and methodology, section 4 discusses the study results, and section 5 concludes the paper.

\section{Previous research}

The various articles on peer effects and obesity published since Christakis and Fowler's (2007) seminal paper are reviewed in Yakusheva et al. (2014), Cunningham et al. (2012), and Nie et al. (2014), all of whom provide substantial evidence that peer effects exist among adolescents and adults. For the purpose of our study, three findings are particularly important: First, although this literature uses several different peer concepts, the most common is the average BMI of friends (e.g., Christakis and Fowler, 2007; de la Haye et al., 2011; Mora and Gil, 2013; Renna et al., 2008; Yakusheva et al., 2011). Nevertheless, some studies use a broader measure, such as the average BMI of a community or school grade (e.g., Trogdon et al., 2008; Asirvatham et al., 2014; Nie et al., 2014). Trogdon et al. (2008), however, argue that these broad versus narrow peer measures define conceptually different reference groups: "broader measures of social networks could operate through the establishment of BMI norms and a reference BMI for body image concerns [...], while more proximal measures of peer effects could operate through influences on diet and physical activity behaviour” (p. 1390). Both peer concepts have been used in past research, and both have given rise to peer effects.

Second, virtually no research exists that analyzes peer effects on obesity among children. In fact, we are aware of only two recent studies: Nie et al. (2014), using China Health and Nutrition Survey data for a sample of 3- to 18-year-olds, demonstrate that peer effects among children aged 3-10 are mostly stronger than those among adolescents. Similarly, Asirvatham et al. (2013), using data from Arkansas schools, identify peer effects among school children up to grade ten but show that estimates for peers within one grade are much larger than those for peers in other grades within the school.

Third, extant research on the peer effects in adolescence is strongly dominated by studies based on U.S. data - and predominantly data from the National Longitudinal Study of Adolescent Health (NLSAH) (e.g., Cohen-Cole and Fletcher, 2008; Renna et al., 2008; Trogdon et al., 2008; Christakis and Fowler, 2007; Halliday and Kwak, 2009; Yang and Huang, 2013). The only non-U.S. studies we know of are de la Haye et al. (2011) for Australia, Leatherdale and Papadakis (2011) for Canada, Mora and Gil (2013) for Spain, Loh 
and Li (2013) for rural China, and Nie et al. (2014) for China, very little of which reports any results for Europe. Yet extending conclusions from U.S. studies to child obesity-related issues in Europe is problematic not only because of the very different institutional setups (Gwozdz et al., 2013) but also because peer effects may differ among cultures and races (Mora and Gil, 2013; Asirvatham et al., 2013). For example, the Mora and Gil (2013) study, which uses BMI data from secondary school students in Spain for peer groups based on nominated classmate friends, finds that the peer effects are stronger than similar effects observed in the U.S.

Finally, all the studies which we are familiar with use BMI, and most rely on self-reported measures (most notably, from the NLSAH). Not only is there some controversy over BMI's reliability as a measure of body fat (especially among children and adolescents) (see Barlow et al., 2007; Burkhauser and Cawley, 2008; Gallagher et al., 1996; McCarthy et al., 2006; Romero-Corral et al., 2006; Wellens et al., 1996; Yusuf et al., 2005), ${ }^{4}$ but epidemiologists tend to have strong reservations about using self-reported data on weight and height because of potential reporting bias (Huybrechts et al., 2006; Shields et al., 2011). Our study therefore uses different measures of fatness to assess peer effects among a sample of European children.

\section{Data and Methods}

\section{The IDEFICS study data}

Our dataset is drawn from the IDEFICS study ("Identification and prevention of Dietary and lifestyle induced health EFfects In Children and infantS”) (see also Ahrens et al., 2011 and Gwozdz et al., 2013 for a more detailed description), a multi-center population-based study on childhood obesity carried out in two selected regions ${ }^{5}$ in each of eight European countries: Belgium, Cyprus, Estonia, Germany, Hungary, Italy, Spain, and Sweden. The child participants were recruited in school and kindergarten settings. One of the study's strengths is that all the children underwent a highly standardized and thorough physical examination (conducted by study nurses, dieticians and medical doctors) to determine body fat, meaning

${ }^{4}$ It should nonetheless be noted that the use of BMI for children is widespread and has been endorsed by an expert committee convened by the American Medical Association (AMA) in collaboration with the U.S. Department of Health and Human Services Health Resources and Services Administration (HRSA) and the CDC (Barlow et al., 2007).

5 The participating regions, which are comparable in their infrastructural, socio-demographic, and socioeconomic characteristics, are as follows: Belgium: Geraardsbergen and Aalter; Cyprus: Strovolos and Paphos; Estonia: Tartu and Tallinn; Germany: Delmenhorst and Wilhelmshaven; Hungary: Pecs and Zalaegerszeg; Italy: Atripalda/Monteforte I/Volturara I and Avellino/Forino/Pratola Serra; Spain: Zaragoza 1. District and Huesca; Sweden: Partille and Alingsas/Mölndal. For a description of the regions, see Bammann et al. (2012). 
that the dataset contains several objective measurements of body fatness. The IDEFICS study also includes detailed information on the children's lifestyle, diets, consumer behavior, parental attitudes, and socio-demographic circumstances. For our study, we analyze such data for a sample of 14,601 children aged two to nine years who participated in both survey waves (2007/08 and 2009/10). These children are from 390 kindergartens and schools, with an average of 41.6 children per setting.

\section{Fatness measures}

Our analysis is based on four fatness measures: (i) measured BMI z-values calculated with International Obesity Task Force (IOTF) growth charts, (ii) measured waist circumference z-values calculated with IOTF growth charts, (iii) body fat (in kilograms) estimated by a composite measure developed using field-derived data on hip circumference, triceps skinfold, and resistance (measured with BIA), and (iv) percentage of body fat (PBF) calculated by body fat $(\mathrm{kg})$ divided by total weight $(\mathrm{kg})$. Our choice of methods was largely determined by the results of an IDEFICS validation study (Bammann et al., 2013), which revealed high performance values for both the waist circumference and composite measures. Although BMI performed less well, it is the most common measure in the peer-effects literature and so is included for practical reasons (for more information on the composite measure, as well as the advantages and disadvantages of the different measures, see Gwozdz et al., 2013).

\section{Peer group definitions}

We use two broad peer group definitions, both based on average fatness measured by BMI $z$-scores, waist circumference z-scores, and body fat. The first definition applies these measures to all children of the same sex in the same school within an age range of one year (excluding the target child) and the second applies it to all children of the same sex in the same school (excluding the target child). These peer groups primarily capture the effect of BMI norms within the setting across the psychosocial mechanisms suggested by Christakis and Fowler (2007), which "rely less on behavioral imitation or modelling and more on changes in individuals' general perceptions of the social norms regarding the acceptability of obesity” (Salvy et al., 2012, p. 374). A priori one could assume that the peer effect of children within the same age group is stronger than for the entire setting. Differences in the effects of these two groups could also be an indication that peer effects indeed exist and are not an artifact of omitted contextual variables (e.g., the nutritional quality of the school meals). It 
should also be noted that such broad measures are more exogenous than those defined using friends (Trogdon et al., 2008), especially with regards to selection and reflection issues. Nevertheless, selection could occur in the form of parents choosing the family residence based on the quality of local schools, which in turn could influence obesity. We are able to partly address this issue by using a fixed-effects specification.

\section{Definitions of weight (mis)perception}

Although research on how peers affect weight perceptions is scarce, especially for children, Blanchflower et al. (2009), using cross-sectional data from the Eurobarometer, do provide evidence that perceptions of overweight depend on peers' BMI among adults (measured as the average BMI in a specific age/gender/country group cell). Assessing the effect of peers on young children's weight perceptions, however, is more difficult because it requires the children's own reports of their weight perceptions, information that is neither readily available nor easy to collect. The IDEFICS survey instead asks for parental perceptions of their children's weight, perceptions that may matter not only because parents play a major role in determining their children's diets and physical activities but because their perceptions may be influenced by the weight of the children's peers (Jones et al., 2012). Specifically, the IDEFICS survey asks parents the following question: “Do you think your child is: (1) Much too underweight? (2) Slightly too underweight? (3) Proper weight? (4) Slightly too overweight? (5) Much too overweight?”. To derive our measures, we match parental responses to this item with the four-category Cole and Lobstein (2012) classification of a child's BMI: (1) thin, (2) normal, (3) overweight, or (4) obese. With this information, we create three dummy variables depicting parental (mis)perceptions: perceiving their children as thinner than they are, accurately assessing their children's weight, or perceiving their children as heavier than they are.

\section{Covariates}

Child characteristics: These characteristics include a child's age, sex, birth weight, premature birth and breastfeeding, as well as three variables capturing health problems during the first four weeks after birth (respiratory problems, infections, and jaundice), four variables indicating the number of younger, older, or same-aged sibling or no siblings, and one variable indicating birth in a foreign country. Birth weight is captured by actual birth weight in grams. The additional dummy variables are non-exclusive breastfeeding and the three health 
problems (respiratory problems, infections, and jaundice). We also include dummy variables capturing the child's country of residency.

Family and parental characteristics: These characteristics include parents' age, foreign country of origin, household size, age of mother at birth, weight gained during pregnancy and smoking during pregnancy (dummy), parental employment (represented by three dummy variables: full-time, part-time, and in school/university, with non-working parents as the reference group), and parental BMI.

Socio-economic variables: These variables include parents' educational level (ISCED 1-6) and household income (net income after taxes and deductions), which is classified into nine categories. To derive comparable income categories by country, we build country-specific categories based on the median equivalent income adjusted for the number of household members. The lowest category is defined by each country's poverty line for a single parent with one child. The middle category is the median country-specific income for a household consisting of two adults and one child (see Bammann et al., 2012, for a more detailed description of these categories).

\section{Statistical analysis}

In a first step, we estimate a pooled ordinary least squares (OLS) model of the following form:

$$
W_{i j}=\alpha_{0}+\alpha_{1} W_{-i j}+\alpha_{2} X_{i j}+\varepsilon_{i}
$$

where $W_{i j}$ is the fatness measure of child $i$ in school $j$, and $W_{-i j}$ is the average measure of fatness in the peer group, excluding individual $i . X_{i j}$ captures the individual, family, parental, and socio-economic control variables; $\varepsilon_{i}$ is the error term; and $\alpha_{1}$ is the endogenous peer effect. Outcomes are clustered at the setting level. OLS estimates based on this model, however, cannot correctly identify the endogenous peer effect because of the reflection problem (Manski, 1993), which stems from the fact that $W_{-i j}$, being computed as the mean fatness of individual i's reference group, is endogenous. This latter is also a source of a simultaneity problem in that the second variable influences the individual's BMI while in turn being influenced by it. Although our broad measure of peer group is more exogenous than measures defined based on friends (Trogdon et al., 2008), this reflection issue may still remain. 
We mitigate this bias by also estimating a fixed-effects model along the lines of Arcidiacono and Nicholson (2005) and Halliday and Kwak (2009), expressed formally as:

$$
W_{i j t}=\alpha_{0}+\alpha_{1} W_{-i j t}+\alpha_{2} X_{i j t}+\mu_{i}+\varepsilon_{i t}
$$

where $W_{i j t}$ is the fatness measure of child $i$ in school $j$ at time $t, X_{i j t}$ depicts the time-variant control variables, $\mu_{i}$ is the time-invariant fixed-effects, and $\varepsilon_{i t}$ is the error term. Although this approach does not necessarily remedy the endogeneity problem, the alternative of using instrumental variables (such as background information on peers) is also not without drawbacks. In particular, as pointed out by Halliday and Kwak (2009), it comes at the expense of increased measurement error and weak instruments. ${ }^{6}$ This inability to totally solve the potential endogeneity problem means that we can draw no conclusions about causality and our estimates must be interpreted as upper bounds (Halliday and Kwak, 2009). In a final step, we analyze parental misperceptions of their children's weight by estimating a pooled logit model using the same specifications as in the pooled OLS case.

\section{Results}

\section{Analysis of the entire sample}

The peer-effect estimates for the entire sample are given in table 1 and the descriptive statistics, in appendix table A1. The first two columns of table 1 report the results for the pooled OLS estimates, and the last two columns, the results for the fixed-effects model. The rows show the results for the four dependent variables; namely, BMI z-score, waist circumference z-score, fat mass in kilograms, and PBF, respectively. For each dependent variable, coefficients are given for both peer definitions.

As the table shows, the peer effects are positive and significant, and the coefficients for the broader definition of peers (i.e., at the setting level) are much smaller than those for the

\footnotetext{
However, in order to identify a causal relationship between peer effects and individual BMI, we also perform a two-stage Generalized Method of Moment (GMM) procedure. Following Renna et al. (2008), Trogdon et al. (2008) and Loh and Li (2013), we adopt average peers' parental BMI as instruments and our results indicate that average peer effects are positive (e.g., coefficient of 0.368 when using BMI z-scores) and significant. We also notice a larger effect of peers when using the broader peer definition (setting) compared to the narrow peer definition (+/- 1 year). We do, however, observe heteroskedasticity (Breusch-Pagan test $=121.10$, p-value $=0.00$ ). The results are available upon request. We do not want to, however, overinterpret these results, because, as pointed out by Cawley and Ruhm (2011), the validity of these instruments is questionable: "friendships could also be selected on the basis of obesity status, with obese youths are relatively likely to have obese parents. This strategy may also suffer from a second-order case of the reflection problem - friend's parents' weight may be affected by friend's weight which in turn may be affected by the respondent's weight” (Cawley and Ruhm, 2011, p. 49).
} 
narrower definition (i.e., children within +/- 1 year). In the case of PBF we even observe a very small negative effect. With regard to the magnitude of the estimated effects, the BMI estimate in the fixed-effects model gives rise to a coefficient of $0.379(0.142)$ when using the narrow (broad) peer definition. The corresponding values for waist circumference are 0.540 and 0.100 for the narrow and broad peer definitions, respectively. Thus, when using waist circumference and a narrow definition, a 1-standard deviation increase in the peer group's average BMI (e.g. a movement from mean BMI to the $85^{\text {th }}$ percentile in the underlying growth chart population; or a movement from mean BMI to overweight) goes hand in hand with a 0.54 standard deviation increase in individual BMI (e.g. a movement from mean BMI to about the $70^{\text {th }}$ percentile in the underlying growth chart population). The results based on fat mass and PBF are easier to interpret: a $1 \mathrm{~kg}$ increase in peer fat mass goes hand in hand with a $235 \mathrm{~g}(89 \mathrm{~g})$ increase in individual fat mass when the narrow (broad) peer definition is used (based on the fixed-effects model). A one percentage point increase in PBF corresponds to a $0.163 \%$ point increase in individual PBF in the fixed-effects model and when using the narrow definition. In general, the peer effects are smaller in the fixed-effects specification. Interestingly, the waist circumference estimates of the peer effect tend to be significantly larger than those for the BMI estimates, particularly under the narrower peer definition. This finding indicates that using other obesity measures than BMI can give rise to substantially different results. Burkhauser and Cawley (2008) show that, among adults, correlation of obesity with employment is sensitive to the definition of obesity, and that BMI is often less significant that more accurate measures of body fat. The authors attribute this insignificance to the inability of BMI to distinguish between total body fat and fat-free mass. Thus, the more significant and stronger measures obtained with waist circumference (compared to BMI) could be due to the fact that, in the IDEFICS study, waist circumference is a more valid measure of body fatness (Bammann et al., 2013), and therefore better able to distinguish between total body fat and fat-free mass.

Our results are generally in line with Asirvatham et al.’s (2013) study of Arkansan children. Their results show that a twofold increase in the obese proportion among peers in the same grade gives rise to an approximately 0.4 standard deviation increase in individual BMI. However, contrary to Asirvatham et al. (2013), we find no pronounced gender differences among our sample of European children (see appendix table A2). In Peng et al.’s (2014) study for China, peer-effect estimates using BMI z-scores among children aged three to nine are, depending on the specification, between 0.2 and 0.1 . 
Table 1: Peer effects for the entire sample - pooled OLS and fixed effects

\begin{tabular}{|c|c|c|c|c|}
\hline & \multicolumn{2}{|c|}{ Pooled OLS } & \multicolumn{2}{|c|}{ Fixed effects } \\
\hline & $\begin{array}{c}\text { Peer: } \\
+/-1 \text { year }\end{array}$ & Peer: setting & $\begin{array}{c}\text { Peer: } \\
+/-1 \text { year }\end{array}$ & Peer: setting \\
\hline \multicolumn{5}{|c|}{ BMI z-score } \\
\hline Peer BMI & $\begin{array}{c}0.267 * * * \\
(0.044)\end{array}$ & $\begin{array}{c}0.214^{* * * *} \\
(0.056)\end{array}$ & $\begin{array}{c}0.379 * * * \\
(0.037)\end{array}$ & $\begin{array}{c}0.142 * * * \\
(0.020)\end{array}$ \\
\hline $95 \%$ CI & {$[0.181,0.353]$} & {$[0.104,0.324]$} & {$[0.306,0.452]$} & {$[0.104,0.181]$} \\
\hline Obs. & 14,566 & 16,549 & 14,566 & 16,549 \\
\hline F-value & 105.31 & 107.26 & 12.55 & 11.71 \\
\hline (p-value) & 0.000 & 0.000 & 0.000 & 0.000 \\
\hline adj./overall R-sqr & 0.227 & 0.223 & 0.048 & 0.030 \\
\hline \multicolumn{5}{|c|}{ Waist circumference $z$-score } \\
\hline Peer waist & $\begin{array}{c}0.403 * * * \\
(0.036)\end{array}$ & $\begin{array}{c}0.171^{* * * *} \\
(0.048)\end{array}$ & $\begin{array}{c}0.540 * * * \\
(0.032)\end{array}$ & $\begin{array}{c}0.100 * * * \\
(0.024)\end{array}$ \\
\hline $95 \% \mathrm{CI}$ & {$[0.332,0.475]$} & {$[0.076,0.266]$} & {$[0.476,0.603]$} & {$[0.053,0.147]$} \\
\hline Obs. & 13,986 & 15,795 & 13,986 & 15,795 \\
\hline F-value & 172.85 & 119.09 & 37.14 & 25.34 \\
\hline (p-value) & 0.000 & 0.000 & 0.000 & 0.000 \\
\hline adj./overall R-sqr & 0.250 & 0.239 & 0.051 & 0.026 \\
\hline \multicolumn{5}{|c|}{ Fat mass (in kg) } \\
\hline Peer fat & $\begin{array}{c}0.698 * * * \\
(0.032)\end{array}$ & $\begin{array}{c}0.269 * * * \\
(0.080)\end{array}$ & $\begin{array}{c}0.235^{* * *} \\
(0.025)\end{array}$ & $\begin{array}{c}0.089 * * * \\
(0.011)\end{array}$ \\
\hline $95 \% \mathrm{CI}$ & $\begin{array}{c}{[0.635} \\
0.761]\end{array}$ & $\begin{array}{c}{[0.111} \\
0.427]\end{array}$ & $\begin{array}{c}{[0.185} \\
0.284]\end{array}$ & $\begin{array}{c}{[0.068,} \\
0.109]\end{array}$ \\
\hline Obs. & 13,001 & 14,601 & 13,001 & 14,601 \\
\hline F-value & 236.58 & 150.52 & 11.99 & 13.08 \\
\hline (p-value) & 0.000 & 0.000 & 0.000 & 0.000 \\
\hline adj./overall R-sqr & 0.390 & 0.336 & 0.131 & 0.051 \\
\hline \multicolumn{5}{|c|}{ Percentage body fat (PBF) } \\
\hline Peer PBF & $\begin{array}{c}0.645 * * * \\
(0.034)\end{array}$ & $\begin{array}{c}-0.158 * \\
(0.063)\end{array}$ & $\begin{array}{c}.163^{* * *} \\
(0.025)\end{array}$ & $\begin{array}{c}-0.032 * * * \\
(0.011)\end{array}$ \\
\hline $95 \%$ CI & {$[0.579,0.711]$} & {$[-0.283,-0.034]$} & {$[0.114,0.212]$} & {$[-0.055,-0.009]$} \\
\hline Obs. & 12,549 & 14,713 & 12,549 & 14,713 \\
\hline F-value & 133.55 & 67.71 & 170.69 & 221.65 \\
\hline (p-value) & 0.000 & 0.000 & 0.000 & 0.000 \\
\hline adj./overall R-sqr & 0.285 & 0.252 & 0.043 & 0.0645 \\
\hline
\end{tabular}

Note: Dependent variables are four obesity measures (BMI z-scores, waist circumference z-scores and fat mass in kg by Bammann et al., 2013, percentage body fat) for children aged 2-9. Pooled OLS regressions include child, family, parental, and socio-economic controls. Fixed-effects model only includes the time-variant controls. Standard error in parentheses. Clustering at the setting level. ${ }^{*} \mathrm{p}<.05,{ }^{* *} \mathrm{p}<.01,{ }^{* * *} \mathrm{p}<.001$ 


\section{Individualism versus collectivism}

One of the unique features of the IDEFICS dataset is that it covers several European regions, making cross-cultural comparisons feasible. Because peer effects may differ among cultures (Mora and Gil, 2013), it is useful to characterize them according to type, with one possibility being individualist versus collectivist. According to Prinstein and Dodge (2008), peer effects may be larger in collectivistic societies: “As a function of culture descriptive constructs such as collectivism and individualism, children are likely to feel different pressures to conform or to be part of the social group. It is possible that the effects of peer influence would be stronger for persons who are sensitive to the collectivistic orientation that may exist in their society. Persons who believe that their culture is characterized by individualism may be more likely to be immune to the effects of peers” (p. 137). According to Hofstede (2001) and Hofstede et al. (2010), Cyprus, Italy, ${ }^{7}$ and Spain are primarily collectivist countries, while Belgium, Estonia, Germany, Hungary, and Sweden are predominantly individualist. To shed light on the collectivist versus individualist hypothesis, we run individual country fixed-effects regressions using the narrow peer definition (see table 2). Our results suggest that collectivist societies may indeed be more susceptible to peer effects, an observation best supported by the analysis based on waist circumference: peer effects in the Spanish, Italian, and Cypriot samples are considerably larger than in the samples for most other countries (with the exception of Estonia). The analysis based on BMI and PBF, however, provides only limited support for the hypothesis, and the analysis based on body fat provides none. Overall, however, we note that the estimated peer effects vary substantially both among countries and among the three measures of fatness. Moreover, despite the reasonably large sample sizes, a number of estimates are not statistically significant. ${ }^{8}$

\footnotetext{
7 According to the Hofstede classification, Italy as a whole is predominantly individualist; however, Southern Italy (where our data were collected) is mostly collectivist.

8 This insignificance persists when we use the pooled OLS model instead of the fixed-effects model.
} 
Table 2: Peer effects by country - fixed effects

\begin{tabular}{|c|c|c|c|c|c|c|c|c|}
\hline & \multicolumn{3}{|c|}{ Collectivistic } & \multicolumn{5}{|c|}{ Individualistic } \\
\hline & ITA & ESP & CYP & BEL & SWE & GER & HUN & EST \\
\hline \multicolumn{9}{|c|}{ BMI z-score } \\
\hline Peer & $0.440^{* * *}$ & -0.033 & $0.402 * * *$ & -0.082 & 0.225 & 0.192 & $0.277^{*}$ & $0.609 * * *$ \\
\hline & $(0.101)$ & $(0.131)$ & $(0.111)$ & $(0.121)$ & $(0.133)$ & $(0.101)$ & $(0.125)$ & $(0.080)$ \\
\hline $95 \%$ CI & $\begin{array}{c}{[0.242} \\
0.637]\end{array}$ & $\begin{array}{c}{[-0.289} \\
0.224]\end{array}$ & $\begin{array}{c}{[0.184} \\
0.620]\end{array}$ & $\begin{array}{c}{[-0.321} \\
0.157]\end{array}$ & $\begin{array}{c}{[-0.037} \\
0.487]\end{array}$ & $\begin{array}{c}{[-0.007} \\
0.391]\end{array}$ & $\begin{array}{c}{[0.031} \\
0.523]\end{array}$ & $\begin{array}{c}{[0.453,} \\
0.766]\end{array}$ \\
\hline Obs. & 2,501 & 1,717 & 1,219 & 1,671 & 2,194 & 1,270 & 2,007 & 1,987 \\
\hline F-value & 6.38 & 5.23 & 4.04 & 1.99 & 1.08 & 1.74 & 1.58 & 3.53 \\
\hline $\begin{array}{l}\text { (p- } \\
\text { value) }\end{array}$ & 0.000 & 0.000 & 0.000 & 0.000 & 0.120 & 0.000 & 0.000 & 0.000 \\
\hline $\begin{array}{l}\text { overall } \\
\text { R-sqr }\end{array}$ & 0.137 & 0.138 & 0.183 & 0.093 & 0.024 & 0.108 & 0.073 & 0.095 \\
\hline \multicolumn{9}{|c|}{ Waist circumference $z$-score } \\
\hline Peer & $0.662^{* * *}$ & $0.624^{* * *}$ & $0.545^{* * *}$ & $0.278^{*}$ & $0.264 * *$ & $0.281^{*}$ & $0.267 * *$ & $0.622 * * *$ \\
\hline & $(0.080)$ & $(0.095)$ & (0.139) & $(0.113)$ & $(0.099)$ & $(0.110)$ & $(0.095)$ & $(0.079)$ \\
\hline $95 \%$ CI & $\begin{array}{c}{[0.505,} \\
0.818]\end{array}$ & $\begin{array}{c}{[0.437} \\
0.811]\end{array}$ & $\begin{array}{c}{[0.271} \\
0.819]\end{array}$ & $\begin{array}{c}{[0.056} \\
0.500]\end{array}$ & $\begin{array}{c}{[0.071} \\
0.458]\end{array}$ & $\begin{array}{c}{[0.064} \\
0.498]\end{array}$ & $\begin{array}{c}{[0.080} \\
0.455]\end{array}$ & $\begin{array}{c}{[0.467} \\
0.776]\end{array}$ \\
\hline Obs. & 2,438 & 1,670 & 1,183 & 1,553 & 2,012 & 1,252 & 1,997 & 1,881 \\
\hline F-value & 12.42 & 7.62 & 1.94 & 5.03 & 4.79 & 10.00 & 4.76 & 8.04 \\
\hline $\begin{array}{l}\text { (p- } \\
\text { value) }\end{array}$ & 0.000 & 0.000 & 0.000 & 0.000 & 0.000 & 0.000 & 0.000 & 0.000 \\
\hline $\begin{array}{l}\text { overall } \\
\text { R-sqr }\end{array}$ & 0.243 & 0.195 & 0.101 & 0.219 & 0.110 & 0.421 & 0.192 & 0.212 \\
\hline \multicolumn{9}{|c|}{ Fat mass (in kg) } \\
\hline Peer fat & $\begin{array}{c}0.079 \\
(0.059)\end{array}$ & $\begin{array}{c}0.029 \\
(0.117)\end{array}$ & $\begin{array}{c}0.530 * * * \\
(0.095)\end{array}$ & $\begin{array}{c}0.159 * \\
(0.070)\end{array}$ & $\begin{array}{l}0.149 * \\
(0.070)\end{array}$ & $\begin{array}{c}0.207 * * \\
(0.071)\end{array}$ & $\begin{array}{c}0.147^{*} \\
(0.068)\end{array}$ & $\begin{array}{c}0.332 * * * \\
(0.071)\end{array}$ \\
\hline $95 \%$ CI & $\begin{array}{c}{[-0.036} \\
0.195]\end{array}$ & $\begin{array}{c}{[-0.201} \\
0.258]\end{array}$ & $\begin{array}{c}{[0.343,} \\
0.716]\end{array}$ & $\begin{array}{c}{[0.022} \\
0.296]\end{array}$ & $\begin{array}{c}{[0.011} \\
0.286]\end{array}$ & $\begin{array}{c}{[0.066} \\
0.348]\end{array}$ & $\begin{array}{c}{[0.013} \\
0.281]\end{array}$ & $\begin{array}{c}{[0.192,} \\
0.473]\end{array}$ \\
\hline Obs. & 2,336 & 1,679 & 1,056 & 1,417 & 1,875 & 1,204 & 1,768 & 1,666 \\
\hline F-value & 1.44 & 0.91 & 5.26 & 2.64 & 3.99 & 4.43 & 1.28 & 6.15 \\
\hline $\begin{array}{l}\text { (p- } \\
\text { value) }\end{array}$ & 0.000 & 0.906 & 0.000 & 0.000 & 0.000 & 0.000 & 0.003 & 0.000 \\
\hline $\begin{array}{l}\text { Overall } \\
\text { R-sqr }\end{array}$ & 0.037 & 0.028 & 0.245 & 0.133 & 0.107 & 0.246 & 0.062 & 0.173 \\
\hline \multicolumn{9}{|c|}{ Percentage body fat (PBF) } \\
\hline $\begin{array}{l}\text { Peer } \\
\text { PBF }\end{array}$ & $0.230 * * *$ & -0.175 & $0.552 * * *$ & 0.185 & $0.222 *$ & 0.143 & 0.196* & -0.009 \\
\hline $\mathrm{PBF}$ & $(0.053)$ & $(0.091)$ & $(0.094)$ & $(0.101)$ & $(0.099)$ & $(0.107)$ & $(0.076)$ & $(0.078)$ \\
\hline $95 \%$ CI & $\begin{array}{c}{[0.126,} \\
0.334]\end{array}$ & $\begin{array}{c}{[-0.353,} \\
0.004]\end{array}$ & $\begin{array}{c}{[0.366} \\
0.737]\end{array}$ & $\begin{array}{c}{[-0.014} \\
0.384]\end{array}$ & $\begin{array}{c}{[0.028} \\
0.416]\end{array}$ & $\begin{array}{c}{[-0.067} \\
0.353]\end{array}$ & $\begin{array}{c}{[0.046} \\
0.346]\end{array}$ & $\begin{array}{c}{[-0.162} \\
0.144]\end{array}$ \\
\hline Obs. & 2,100 & 1,660 & 1,082 & 1,675 & 1,425 & 1,608 & 1,219 & 1,780 \\
\hline F-value & 52.18 & 21.01 & 28.90 & 39.06 & 22.15 & 18.10 & 42.68 & 15.80 \\
\hline $\begin{array}{l}\text { (p- } \\
\text { value) } \\
\text { Overall }\end{array}$ & 0.000 & 0.000 & 0.000 & 0.000 & 0.000 & 0.000 & 0.000 & 0.000 \\
\hline R-sqr & .057 & .041 & .039 & .076 & .023 & .087 & 0.001 & 0.028 \\
\hline
\end{tabular}


Note: Dependent variables are four obesity measures (BMI z-scores, waist circumference z-scores and fat mass in kg by Bammann et al., 2013, percentage body fat) for children aged 2-9. Fixed-effects model only includes the time-variant controls. The regions are: Belgium: Geraardsbergen and Aalter; Cyprus: Strovolos and Paphos; Estonia: Tartu and Tallinn; Germany: Delmenhorst and Wilhelmshaven; Hungary: Pecs and Zalaegerszeg; Italy: Atripalda/Monteforte I/Volturara I and Avellino/Forino/Pratola Serra; Spain: Zaragoza 1. District and Huesca; Sweden: Partille and Alingsas/Mölndal. Standard error in parentheses. $* \mathrm{p}<.05, * * \mathrm{p}<.01, * * * \mathrm{p}<.001$

\section{Effect of peers on parental perceptions}

As in several other studies (see Parry et al., 2008, for a meta-analysis), our results also confirm a clear disconnect in parental perceptions of their child's weight status. According to the descriptive statistics for all children in both waves (see table 3), only $14 \%$ of the parental perceptions correctly identified obesity in their child, while over half misperceived overweight.

Table 3: Parental (mis)perceptions of child weight

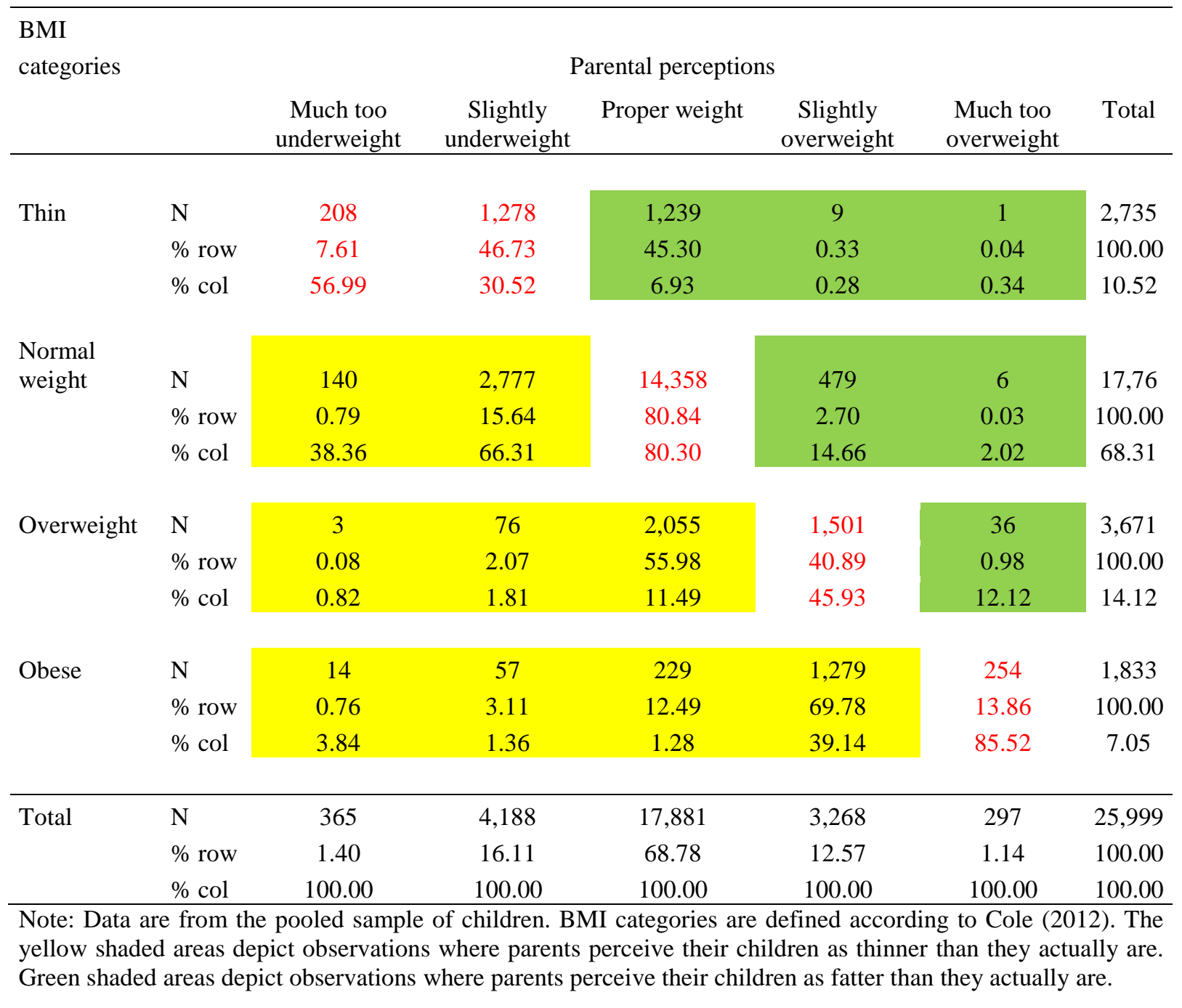


These misperceptions are clearly tied to peer weight. According to the logit estimates of the relation between average peer fatness and parental perceptions of their child's weight (table 4), a larger probability of parents perceiving their child as thinner than he or she really is (with odds ratios ranging from 1.046 to 1.280) goes hand in hand with higher levels of peer fatness. This result, however, applies only to the narrow peer definition and is particularly pronounced in parents' perceptions of their boys (see appendix table A3). When using BMI as our measure of fatness, we also observe a significant negative association between peer's BMI and the probability of parents perceiving their children as fatter than they are. That is, the lower the peer's BMI, the more likely that parents will consider their child fatter than he or she actually is.

Table 4: Peer effects and parental misperceptions - logit model

\begin{tabular}{|c|c|c|c|c|}
\hline & \multicolumn{2}{|c|}{ Weight perception: thinner } & \multicolumn{2}{|c|}{ Weight perception: fatter } \\
\hline & Peer: +/- 1 year & Peer: setting & Peer: +/- 1 year & Peer: setting \\
\hline \multicolumn{5}{|c|}{ BMI z-score } \\
\hline \multirow[t]{2}{*}{ Peer BMI } & $1.280 * * *$ & 1.027 & $0.587 * * *$ & $0.630 * *$ \\
\hline & $(0.088)$ & $(0.076)$ & $(0.078)$ & $(0.106)$ \\
\hline $95 \% \mathrm{CI}$ & {$[1.119,1.464]$} & {$[0.889,1.187]$} & {$[0.452,0.761]$} & {$[0.453,0.875]$} \\
\hline $\mathrm{N}$ & 14,566 & 16,549 & 14,566 & 16,549 \\
\hline $\mathrm{Ll}$ & $-7,474$ & $-8,493$ & $-3,408$ & $-3,989$ \\
\hline df_m & 34 & 34 & 34 & 34 \\
\hline Aic & 15,017 & 17,057 & 6,888 & 8,048 \\
\hline Bic & 15,283 & 17,327 & 7,153 & 8,318 \\
\hline \multicolumn{5}{|c|}{ Waist circumference $z$-score } \\
\hline \multirow[t]{2}{*}{ Peer waist } & $1.221 * * *$ & 1.024 & 0.935 & 0.989 \\
\hline & $(0.068)$ & $(0.069)$ & $(0.105)$ & $(0.154)$ \\
\hline $95 \% \mathrm{CI}$ & {$[1.094,1.362]$} & {$[0.897,1.170]$} & {$[0.751,1.165]$} & {$[0.729,1.341]$} \\
\hline $\mathrm{N}$ & 14,566 & 16,549 & 14,566 & 16,549 \\
\hline $\mathrm{Ll}$ & $-7,474$ & $-8,493$ & $-3,424$ & $-4,000$ \\
\hline df_m & 34 & 34 & 34 & 34 \\
\hline Aic & 15,019 & 17,057 & 6,919 & 8,071 \\
\hline Bic & 15,285 & 17,327 & 7,184 & 8,341 \\
\hline \multicolumn{5}{|c|}{ Fat mass (in kg) } \\
\hline Peer fat & $1.046 * *$ & 1.024 & 0.952 & 0.937 \\
\hline & $(0.016)$ & $(0.022)$ & $(0.031)$ & $(0.037)$ \\
\hline $95 \%$ CI & {$[1.015,1.078]$} & {$[0.981,1.068]$} & {$[0.894,1.014]$} & {$[0.866,1.013]$} \\
\hline $\mathrm{N}$ & 14,367 & 16,339 & 14,367 & 16,339 \\
\hline 11 & $-7,365$ & $-8,371$ & $-3,353$ & $-3,940$ \\
\hline
\end{tabular}




\begin{tabular}{lcc|cc} 
df_m & 34 & 34 & 34 & 34 \\
aic & 14,800 & 16,811 & 6,776 & 7,951 \\
bic & 15,065 & 17,081 & 7,041 & 8,220 \\
\hline \multicolumn{4}{c}{ Percentage body fat (PBF) } \\
\hline Peer PBF & $1.039 * * *$ & 1.024 & $0.970 *$ & 1.001 \\
& $(0.007)$ & $(0.022)$ & $(0.013)$ & $(0.011)$ \\
95\% CI & {$[1.025,1.053]$} & {$[0.981,1.068]$} & {$[0.945,0.995]$} & {$[0.979,1.023]$} \\
& & & 16,473 \\
N & 13,922 & 16,339 & 13,922 & $-3,978$ \\
Ll & $-7,134$ & $-8,447$ & $-3,268$ & 34 \\
df_m & 34 & 34 & 34 & 8,024 \\
Aic & 14,337 & 16.9611 & 6,604 & 8,286 \\
Bic & 14,594 & 17,223 & 6,860 & \\
\hline
\end{tabular}

Note: Dependent variable in the first two (last two) columns has a value equal to "1" if the parent perceives the child to be thinner (heavier) than it actually is; zero otherwise. Odd ratios are presented in the table. The analysis is conducted for children aged 2-9. Regressions include child, family, parental, and socio-economic controls. Standard error in parentheses. Clustering at the setting level. ${ }^{*} \mathrm{p}<.05,{ }^{* *} \mathrm{p}<.01,{ }^{* * *} \mathrm{p}<.001$

These results support the notion that peer fatness affects parental perceptions; that is, in forming their perceptions of their own child's weight, parents make comparisons with their children's friends and classmates, a phenomenon also observed in the qualitative study by Jones et al. (2012).

\section{Conclusions}

This paper uses data on more than 14,000 children aged two to nine in 16 regions of eight European countries from the first two waves of the IDEFICS survey in order to analyze the effects that peers may have on child obesity. Scant empirical evidence of peer effects in Europe exists, and we are only aware of one study (Mora and Gil, 2013) that addresses peer effect on adolescents in Spain. Furthermore, we are only aware of two non-European studies that analyze the effects that peers may have on child obesity (namely Peng et al., 2014 and Asirvatham, 2013). This is surprising as there is ample research in many disciplines that show effects of peers on several child behaviors and outcomes including school achievement (Burke and Sass, 2013), eating behavior and physical activity (Salvy et al., 2012). The main reason for this dearth of research on children is the lack of adequate data. The IDEFICS study is one of the few large-scale surveys that collects reliable information on child obesity. Our results in fact show that, even after we control for a rich set of covariates and unobserved heterogeneity, a child's fatness is related to the average fatness of the same-sex similarly aged 
children in the same school. Although we cannot rule out an upward bias from the reflection issue despite our use of broad peer definitions and fixed-effects estimations to mitigate this problem, our findings still provide clear support for the existence of peer effects in the European sample.

Another unique feature of the IDEFICS dataset is that it provides strong objective measures of child fatness, including waist circumference, imputed body fat, and percentage body fat. The inclusion of these additional measures provides clear evidence that different measures give rise to different results, with waist circumference generally producing larger peer effect estimates than BMI. The fact that the IDEFICS study covers several regions in eight European countries also allows a useful cross-cultural comparison of peer effects, which shows substantial variation among the regions, with generally larger effects in the Spanish, Italian, and Cypriot regions than in the German, Swedish, Belgian, and Hungarian areas. One tentative explanation for this observation - and one in line with the hypotheses put forward by Mora and Gil (2013) and Prinstein and Dodge (2008) - is that peer pressure may be larger in more collectivist societies.

Little is known about the mechanisms of peer effects among children. Do they, for example, work through "peer pressure”, leading children to imitate peers' eating and physical activity behavior, or do peers simply influence changes in individuals' general perceptions of the social norms for obesity's acceptability (Salvy et al., 2012)? In this paper, we throw some light on this aspect by examining the association between peer fatness and parental perceptions of their own children's weight. We show that increases in peer fatness go hand in hand with a higher probability of parents misperceiving their children as being thinner than they actually are. Although our analysis cannot claim to show a causal link between these misperceptions and peer fatness, it supports existing evidence that parents tend to assess their offspring's weight based on comparisons with their children's friends and classmates.

Identifying and understanding peer effects on child obesity is extremely important, not only because of ample evidence that childhood obesity persists into adulthood (Guo and Chumlea, 1999) but because healthy lifestyles (including eating habits and adequate physical activity) are formed at young ages and continue into adolescence and adulthood. In addition, knowing how and to what extent peers influence lifestyle choices in different cultural setting raises many interesting questions for further investigation. 


\section{Acknowledgment}

This study was conducted as part of the IDEFICS study (http://www.idefics.eu). We gratefully acknowledge the financial support of the European Community within the Sixth RTD Framework Programme under Contract No. 016181 (FOOD). We are thankful for valuable comments made by two anonymous reviewers.

\section{References}

Ahrens, W., Bammann, K., Siani, A., Buchecker, K., De Henauw, S., Iacoviello, L., Hebestreit, A., Krogh, V., Lissner, L., Mårild, S., Molnár, D., Moreno, L.A., Pitsiladis, Y.P., Reisch, L., Tornaritis, M., Veidebaum, T., Pigeot, I., 2011. The IDEFICS cohort: design, characteristics and participation in the baseline survey. International Journal of Obesity 35, 3-15.

Arcidiacono, P., Nicholson, S., 2005. Peer effects in medical school. Journal of Public Economics 89, 327-350.

Asirvatham, J., Nayga, Jr., R.M., Thomsen, M.R., 2013. Peer-effects on child obesity. Paper presented at the Agricultural \& Applied Economics Association's 2013 AAEA \& CAES Joint Annual Meeting Washington, DC, August 4-6, 2013.

Asirvatham, J., Nayga, Jr., R.M., Thomsen, M.R., 2014. Peer-effects on obesity among public elementary school children: A grade-level analysis. Applied Economic Perspectives and Policy 36(3), 438-459.

Balsa, A.I., Homer, J.F., French, M.T., Norton, E.C., 2011. Alcohol Use and Popularity: Social Payoffs From Conforming to Peers' Behavior. Journal of Research on Adolescence 21, 559-568.

Bammann, K., Gwozdz, W., Lanfer, A., Barba, G., De Henauw, S., Eiben, G., FernandezAlvira, J.M., Kovac, E., Lissner, L., Moreno, L.A., Tornaritis, M., Veidebaum, T., Pigeot, I., 2012. Socioeconomic factors and childhood overweight in Europe: results from the multi-centre IDEFICS study. Pediatric Obesity 8, 1-12.

Bammann, K., Huybrechts, I., Vicente-Rodriguez, G., Easton, C., De Vriendt, T., Marild, S., Mesana, M.I., Peeters, M.W., Reilly, J.J., Sioen, I., Tubic, B., Wawro, N., Wells, J.C., Westerterp, K., Pitsiladis, Y., Moreno, L.A., 2013. Validation of anthropometry and foot- 
to-foot bioelectrical resistance against a three-component model to assess total body fat in children: the IDEFICS study. International Journal of Obesity 37(4), 520-526.

Barlow, S.E., Expert Committee, 2007. Expert Committee Recommendations Regarding the Prevention, Assessment, and Treatment of Child and Adolescent Overweight and Obesity: Summary Report. Pediatrics 120, 164-192.

Blanchflower, D.G., Landeghem, B., Oswald, A.J., 2009. Imitative obesity and relative utility. Journal of the European Economic Association 7(2-3), 528-538.

Burke, M.A., Sass, T.R., 2013. Classroom peer effects and student achievement. Journal of Labor Economics 31(1), 51-82.

Burkhauser, R.V., Cawley, J., 2008. Beyond BMI: The value of more accurate measures of fatness and obesity in social science research. Journal of Health Economics 27(2), 519529.

Cawley, J., Ruhm, C., 2011. The Economics of Risky Behaviors, NBER Working Paper No. 17081.

Christakis, N.A., Fowler, J.H., 2007. The spread of obesity in a large social network over 32 years. New England Journal of Medicine 357, 370-379.

Cohen-Cole, E., Fletcher, J.M., 2008. Is obesity contagious? Social networks vs. environmental factors in the obesity epidemic. Journal of Health Economics 27(5), 13821387.

Cole, T.J.,Lobstein, T., 2012. Extended international (IOTF) body mass index cut-offs for thinness, overweight and obesity. Pediatric Obesity 7, 284-294., 2000. Establishing a standard definition for child overweight and obesity worldwide, international survey. BMJ 320 (7244), 1240-1243.

Cunningham, S.A., Vaquera, E., Maturo, C.C., Narayan, K.M.V., 2012. Is there evidence that friends influence body weight? A systematic review of empirical research. Social Science \& Medicine 75, 1175-1183.

De la Haye, K., Robins, G., Mohr, P., Wilson, C., 2011. Homophily and contagion as explanations for weight similarities among adolescent friends. Journal of Adolescent Health 49(4), 421-427.

Dishion, T.J., Tipsord, J.M., 2011. Peer Contagion in Child and Adolescent Social and Emotional Development. Annual Review of Psychology 62, 189-214. 
European Commission (EC), 2010. A strategy for Europe on nutrition, overweight and obesity related health issues. Implementation progress report. Brussels.

Gallagher, D., Visser, M., Sepulveda, D., Pierson R.N., Harris, T., Heymsfield, S.B, 1996. How useful is body mass index for comparison of body fatness across age, sex, and ethnic groups? American Journal of Epidemiology 143(3), 228-239.

Guo, S.S., Chumlea, W.C., 1999. Tracking of body mass index in children in relation to overweight in adulthood. American Journal of Clinical Nutrition 70(1), 145s-148s.

Gwozdz, W., Sousa-Poza, A., Reisch, L.A., Ahrens, W., Eiben, G., Fernandéz-Alvira, J., Hadjigeorgiou, C., De Henauw, S., Kovács, E., Lauria, F., 2013. Maternal employment and childhood obesity - A European perspective. Journal of Health Economics 32(4), 728-742.

Halliday, T.J., Kwak, S., 2009. Weight gain in adolescents and their peers. Economics and Human Biology 7(2), 181-190.

Hammond, R., 2010. Social influence and obesity. Current Opinion in Endocrinology, Diabetes \& Obesity 17(5), 467-471.

Hofstede, G., 2001. Culture’s Consequences: Comparing Values, Behaviors, Institutions, and Organizations Across Nations. Second Edition, Thousand Oaks CA: Sage Publications.

Hofstede G., Hofstede G.J., Minkov, M., 2010. Cultures and Organizations: Software of the Mind. Revised and Expanded $3^{\text {rd }}$ Edition. New York: McGraw-Hill USA.

Huybrechts, I., De Bacquer, D., Van Trimpont, I., De Backer, G., De Henauw, S., 2006. Validity of parentally reported weight and height for preschool-aged children in Belgium and its impact on classification into body mass index categories. Pediatrics 118(5), 21092018.

Jones, A.R., Parkinson, K.N., Drewett, R.F, Hyland, R.M., Pearce, M.S., Adamson, A.J., Gateshead Millennium Study core team, 2012. Parental perceptions of weight status in children: the Gateshead Millennium Study. International Journal of Obesity 35(7), 953962.

Larson, N.I., Wall, M.M., Story, M.T., Neumark-Sztainer, D.R., 2013. Home/family, peer, school, and neighborhood correlates of obesity in adolescents. Obesity 21(9), 1858-1869.

Leatherdale, S., Papadakis,S., 2011. A multi-level examination of the association between older social models in the school environment and overweight and obesity among younger students. Journal of Youth and Adolescence 40(3), 361-372. 
Loh, C.A., Li, Q., 2013. Peer effects in adolescent bodyweight: Evidence from rural China. Social Science \& Medicine 86, 35-44.

Manski, C.F., 1993. Identification of endogenous social effects: The reflection problem. Review of Economic Studies 60(3), 531-542.

McCarthy, H.D., Cole, T.J., Fry, T., Jebb, S.A., Prentice, A.M., 2006. Body fat reference curves for children. International Journal of Obesity 30, 598-602.

Mercken, L., Steglich, C., Sinclair, P., Holliday, J., Moore, L., 2012. A longitudinal social network analysis of peer influence, peer selection, and smoking behavior among adolescents in British schools. Health Psychology 31(4), 450-459.

Mora, T., Gil, J., 2013. Peer effects in adolescent BMI: Evidence from Spain. Health Economics 22(5), 501-516.

Nie, P., Sousa-Poza, A., He, X., 2014. Peer effects on childhood and adolescent obesity in China, IZA Discussion Paper No. 8528.

Parry, L.L., Netuveli, G., Parry, J., Saxena, S., 2008. A systematic review of parental perception of overweight status in children. Journal of Ambulatory Care Management 31, 253-268.

Prinstein, M.J., Dodge, K.A., 2008. Understanding Peer Influence in Children and Adolescents, Guilford Press.

Renna, F. Grafova, I.B., Thakur, N., 2008. The effect of friends on adolescent body weight. Economics and Human Biology 6(3), 377-387.

Romero-Corral, A., Montori, V.M., Somers, V.K., Korinek, J., Thomas, R.J., Allison, T.G., Mookadam, F., Lopez-Jimenez, F., 2006. Association of bodyweight with total mortality and with cardiovascular events in coronary artery disease: a systematic review of cohort studies. The Lancet 368(9536), 666-678.

Salvy S-J, De la Haye, K., Bowker, J.C., Hermans, R.C.J., 2012. Influence of peers and friends on children's and adolescents' eating and activity behaviors. Physiology \& Behavior 106, 369-378.

Schwartz, D.L., Chase, C.C., Oppezzo, M.A., Chin, D.B., 2011. Practicing versus inventing with contrasting cases: The effects of telling first on learning and transfer. Journal of Educational Psychology 103(4), 759-775. 
Shields, M., Connor Gorber, S., Janssen, I., Tremblay, M.S., 2011. Obesity estimates for children based on parent-reported versus direct measures. Health Reports 22, 1-12.

Trogdon, J.G., Nonnemaker, J., Pais, J., 2008. Peer effects in adolescent overweight. Journal of Health Economics 27(5), 1388-1399.

Trogdon, J.G., Allaire, B.T., 2014. The Effect of Friend Selection on Social Influences in Obesity. Economics and Human Biology (in press).

Valente, T.W., Fujimoto, K., Chou, C.P., Spruijt-Metz, D., 2009. Adolescent affiliations and adiposity: A social network analysis of friendships and obesity. Journal of Adolescent Health 45(2), 202-204.

Wal, J.S.V, 2012. The relationship between body mass index and unhealthy weight control behaviors among adolescents: The role of family and peer social support. Economics and Human Biology 10, 395-404.

Wellens, R.I., Roche, A.F., Khamis, H.J., Jackson, A.S., Pollock, M.L., Siervogel, R.M., 1996. Relationships between the body mass index and body composition. Obesity Research 4, 35-44.

World Health Organization (WHO), 2009. Prevelance of overweight and obesity in children and adolescents, fact sheet 2.3, December 2009, code: RPG2_ous_E2.

Yakusheva, O., Kapinos, K.A., Eisenberg, D., 2014. Estimating Heterogeneous and Hierarchical Peer Effects on Body Weight Using Roommate Assignments as a Natural Experiment. Journal of Human Resources 49(1), 234-261.

Yakusheva, O., Kapinos, K.A., Weiss, D., 2011. Peer effects and the Freshman 15: Evidence from a natural experiment. Economics and Human Biology 9, 119-132.

Yang, M.Z., Huang, R., 2013. Asymmetric association between exposure to obesity and weight gain among adolescents. Eastern Economic Journal 40(1), 96-118.

Yusuf, S., Hawken, S., Ounpuu, S., Bautista, L., Grazia Franzosi, M., Commerford, P., Lang, C.C., Rumboldt, Z., Onen, C.L., Lisheng, L., Tanomsup, S., Wangai, P., Razak, F., Sharma, A.M., Anand, S.S., 2005. Obesity and the risk of myocardial infarction in 27,000 participants from 52 countries: a case-control study. The Lancet 366, 1640-1649. 


\section{Appendix}

Table A1: Descriptive statistics (pooled sample)

\begin{tabular}{|c|c|c|c|}
\hline Variable & Obs. & Mean & Std. Dev. \\
\hline \multicolumn{4}{|l|}{ Weight status } \\
\hline BMI z-score & 27,341 & 0.310 & 1.362 \\
\hline Waist circumference z-score & 25,964 & 0.383 & 1.379 \\
\hline Fat mass (kg) & 23,650 & 4.051 & 3.571 \\
\hline Percentage body fat (\%) & 23,650 & 13.986 & 9.006 \\
\hline \multicolumn{4}{|l|}{ Weight perception } \\
\hline Thinner (dummy) & 27,345 & 0.242 & 0.429 \\
\hline Fatter (dummy) & 27,345 & 0.104 & 0.305 \\
\hline \multicolumn{4}{|l|}{ Peer weight status } \\
\hline Peer BMI (+/- 1 year) & 23,927 & 0.335 & 0.563 \\
\hline Peer BMI (Setting) & 27,344 & 0.310 & 0.380 \\
\hline Peer waist circumference (+/- 1 year) & 23,927 & 0.383 & 0.641 \\
\hline Peer waist circumference (Setting) & 27,344 & 0.380 & 0.419 \\
\hline Peer fat mass (+/- 1 year) & 23,521 & 4.034 & 2.102 \\
\hline Peer fat mass (Setting) & 27,037 & 4.010 & 1.250 \\
\hline Peer percentage body fat (+/- 1 year) & 22,694 & 13.738 & 4.637 \\
\hline Peer percentage body fat (setting) & 27,033 & 11,925 & 4.962 \\
\hline \multicolumn{4}{|l|}{ Child characteristics } \\
\hline Age child (years) & 27,345 & 6.401 & 2.077 \\
\hline Sex child (dummy) & 27,344 & 0.497 & 0.500 \\
\hline Audiovisual media time (hours/week) & 25,115 & 12.694 & 7.517 \\
\hline Siblings: older (\#) & 27,344 & 0.615 & 0.835 \\
\hline Siblings: same age (\#) & 27,344 & 0.037 & 0.205 \\
\hline Siblings: younger (\#) & 27,344 & 0.437 & 0.639 \\
\hline Siblings: none (dummy) & 27,344 & 0.111 & 0.314 \\
\hline Country of birth child & 26,736 & 0.017 & 0.129 \\
\hline \multicolumn{4}{|l|}{ Birth factors } \\
\hline Birth weight & 25,513 & 3334,229 & 569,450 \\
\hline Premature birth (dummy) & 26,127 & 0.271 & 0.444 \\
\hline Breastfed (dummy) & 25,151 & 0.524 & 0.499 \\
\hline Respiratory problems & 27,344 & 0.029 & 0.166 \\
\hline Infection & 27,344 & 0.024 & 0.154 \\
\hline Jaundice & 27,344 & 0.121 & 0.326 \\
\hline Mother age at birth & 24,492 & 29.314 & 5.033 \\
\hline Weight gain during pregnancy & 23,963 & 14.240 & 6.038 \\
\hline Pregnancy: smoking & 27,344 & 0.129 & 0.335 \\
\hline \multicolumn{4}{|l|}{ Parental characteristics } \\
\hline Age mother & 25,973 & 36.143 & 5.432 \\
\hline Age father & 23,931 & 39.049 & 5.995 \\
\hline BMI mother & 25,207 & 23.904 & 4.292 \\
\hline BMI father & 22,528 & 26.470 & 3.662 \\
\hline Country of birth mother & 26,712 & 0.074 & 0.262 \\
\hline Country of birth father & 26,650 & 0.069 & 0.253 \\
\hline ISCED (max in household) & 25,910 & 3.900 & 1.200 \\
\hline
\end{tabular}




\begin{tabular}{llll} 
Household monthly net income & 23,492 & 5.478 & 2.458 \\
\hline Country & & & \\
\hline Italy & 27,344 & 0.140 & 0.347 \\
Estonia & 27,344 & 0.121 & 0.326 \\
Cyprus & 27,344 & 0.145 & 0.352 \\
Belgium & 27,344 & 0.121 & 0.327 \\
Sweden & 27,344 & 0.122 & 0.327 \\
Germany & 27,344 & 0.110 & 0.313 \\
Hungary & 27,344 & 0.141 & 0.348 \\
Spain & 27,344 & 0.100 & 0.300 \\
\hline
\end{tabular}

Table A2: Peer effects by gender - pooled OLS and fixed effects

\begin{tabular}{|c|c|c|c|c|c|c|c|c|}
\hline \multirow[t]{3}{*}{$\begin{array}{l}\text { Model (2) } \\
\text { controls }\end{array}$} & \multicolumn{4}{|c|}{ Pooled OLS } & \multicolumn{4}{|c|}{ Fixed Effects } \\
\hline & \multicolumn{2}{|c|}{ Peers: +- 1year } & \multicolumn{2}{|c|}{ Peers: setting } & \multicolumn{2}{|c|}{ Peers: +- 1year } & \multicolumn{2}{|c|}{ Peers: setting } \\
\hline & Girls & Boys & Girls & Boys & Girls & Boys & Girls & Boys \\
\hline \multicolumn{9}{|c|}{ BMI z-score } \\
\hline Peer BMI & $0.177^{* *}$ & $0.338 * * *$ & $0.171^{* *}$ & $0.250 * * *$ & $0.389 * * *$ & $0.382 * * *$ & $0.133^{* * *}$ & $0.152^{* * *}$ \\
\hline SE & $\begin{array}{c}(0.064) \\
{[0.051,0.3}\end{array}$ & $\begin{array}{c}(0.057) \\
{[0.226,0.4}\end{array}$ & $\begin{array}{c}(0.063) \\
{[0.048,0.2}\end{array}$ & $\begin{array}{c}(0.069) \\
{[0.115,0.3}\end{array}$ & $\begin{array}{c}(0.055) \\
{[0.281,0.4}\end{array}$ & $\begin{array}{c}(0.052) \\
{[0.279,0.4}\end{array}$ & $\begin{array}{c}(0.028) \\
{[0.078,0.1}\end{array}$ & $\begin{array}{c}(0.028) \\
{[0.098,0.2}\end{array}$ \\
\hline CI95 & $04]$ & 49] & 94] & 85] & 96] & 85] & 89] & $06]$ \\
\hline Obs. & 7139 & 7427 & 8159 & 8390 & 7139 & 7427 & 8159 & 8390 \\
\hline F-value & 72.28 & 76.28 & 66.82 & 62.70 & 6.99 & 7.57 & 5.85 & 7.44 \\
\hline (p-value) & 0.000 & 0.000 & 0.000 & 0.000 & 0.000 & 0.000 & 0.000 & 0.000 \\
\hline adj. R-sqr & 0.213 & 0.244 & 0.212 & 0.235 & 0.059 & 0.061 & 0.044 & 0.053 \\
\hline \multicolumn{9}{|c|}{ Waist circumference z-score } \\
\hline Peer waist & $0.387 * * *$ & $0.409 * * *$ & $0.213^{* * *}$ & $0.114^{*}$ & $0.552^{* * *}$ & $0.547 * * *$ & $0.132^{* * *}$ & $0.066^{*}$ \\
\hline SE & $\begin{array}{c}(0.049) \\
{[0.290,0.4}\end{array}$ & $\begin{array}{c}(0.046) \\
{[0.318,0.5}\end{array}$ & $\begin{array}{c}(0.056) \\
{[0.102,0.3}\end{array}$ & $\begin{array}{c}(0.058) \\
{[0.001,0.2}\end{array}$ & $\begin{array}{c}(0.046) \\
{[0.461,0.6}\end{array}$ & $\begin{array}{c}(0.046) \\
{[0.458,0.6}\end{array}$ & $\begin{array}{c}(0.035) \\
{[0.063,0.2}\end{array}$ & $\begin{array}{c}(0.033) \\
{[0.001,0.1}\end{array}$ \\
\hline CI95 & 84] & 00] & 23] & 28] & 42] & $36]$ & $02]$ & 30] \\
\hline Obs. & 6876 & 7110 & 7797 & 7998 & 6876 & 7110 & 7797 & 7998 \\
\hline F-value & 85.50 & 118.21 & 67.51 & 81.93 & 19.20 & 24.13 & 12.88 & 17.16 \\
\hline (p-value) & 0.000 & 0.000 & 0.000 & 0.000 & 0.000 & 0.000 & 0.000 & 0.000 \\
\hline adj. R-sqr & 0.226 & 0.272 & 0.220 & 0.255 & 0.156 & 0.183 & 0.097 & 0.124 \\
\hline \multicolumn{9}{|c|}{ Fat mass (in kg) } \\
\hline Peer fat & $0.677 * * *$ & $0.710^{* * *}$ & $0.218^{* *}$ & $0.313^{* * *}$ & $0.226^{* * *}$ & $0.240^{* * *}$ & $0.080^{* * *}$ & $0.096^{* * *}$ \\
\hline SE & $(0.036)$ & (0.038) & $(0.080)$ & $(0.085)$ & $(0.038)$ & $(0.035)$ & $(0.015)$ & $(0.015)$ \\
\hline CI95 & $\begin{array}{c}{[0.607,0.7} \\
48]\end{array}$ & $\begin{array}{c}{[0.636,0.7} \\
84]\end{array}$ & $\begin{array}{c}{[0.060,0.3} \\
76]\end{array}$ & $\begin{array}{c}{[0.145,0.4} \\
80]\end{array}$ & $\begin{array}{c}{[0.151,0.3} \\
00]\end{array}$ & $\begin{array}{c}{[0.171,0.3} \\
10]\end{array}$ & $\begin{array}{c}{[0.051,0.1} \\
08]\end{array}$ & $\begin{array}{c}{[0.066,0.1} \\
26]\end{array}$ \\
\hline Obs. & 6367 & 6634 & 7191 & 7410 & 6367 & 6634 & 7191 & 7410 \\
\hline F-value & 136.92 & 166.27 & 101.73 & 86.98 & 4.81 & 9.27 & 5.37 & 10.18 \\
\hline (p-value) & 0.000 & 0.000 & 0.000 & 0.000 & 0.000 & 0.000 & 0.000 & 0.000 \\
\hline adj. R-sqr & 0.388 & 0.369 & 0.340 & 0.311 & 0.049 & 0.083 & 0.044 & 0.080 \\
\hline
\end{tabular}


Note: Dependent variables are four obesity measures (BMI z-scores, waist circumference z-scores and fat mass in kg by Bammann et al., 2013, percentage body fat) for children aged 2-9. Pooled OLS regressions include child, family, parental, and socio-economic controls. Fixed-effects model only includes the time-variant controls. Standard error in parentheses. Clustering at the setting level. ${ }^{*} \mathrm{p}<.05,{ }^{* *} \mathrm{p}<.01,{ }^{* * *} \mathrm{p}<.001$

Table A3: Peer effects and parental misperceptions by gender - logit model

\begin{tabular}{|c|c|c|c|c|c|c|c|c|}
\hline & \multicolumn{4}{|c|}{ Weight perception: thinner } & \multicolumn{4}{|c|}{ Weight perception: fatter } \\
\hline & \multicolumn{2}{|c|}{ Peers: +- 1year } & \multicolumn{2}{|c|}{ Peers: setting } & \multicolumn{2}{|c|}{ Peers: +- 1year } & \multicolumn{2}{|c|}{ Peers: setting } \\
\hline & girls & boys & girls & boys & girls & boys & girls & boys \\
\hline \multicolumn{9}{|c|}{ BMI z-score } \\
\hline Peer BMI & 1.190 & $1.351^{* * *}$ & 1.038 & 1.021 & $0.684 * *$ & $0.485^{* * *}$ & 0.764 & $0.518 * *$ \\
\hline $95 \% \mathrm{CI}$ & $\begin{array}{c}(0.127) \\
{[0.966} \\
1.467]\end{array}$ & $\begin{array}{c}(0.122) \\
{[1.132} \\
1.613]\end{array}$ & $\begin{array}{c}(0.087) \\
{[0.881} \\
1.222]\end{array}$ & $\begin{array}{c}(0.106) \\
{[0.833,} \\
1.252]\end{array}$ & $\begin{array}{c}(0.098) \\
{[0.518} \\
0.905]\end{array}$ & $\begin{array}{c}(0.096) \\
{[0.329} \\
0.717]\end{array}$ & $\begin{array}{c}(0.148) \\
{[0.522,} \\
1.118]\end{array}$ & $\begin{array}{c}(0.104) \\
{[0.350} \\
0.767]\end{array}$ \\
\hline $\mathrm{N}$ & 7,139 & 7,427 & 8,159 & 8,390 & 7,139 & 7,427 & 8,159 & 8,390 \\
\hline $\mathrm{Ll}$ & $-3,528$ & $-3,922$ & $-4,057$ & $-4,410$ & $-1,790$ & $-1,592$ & $-2,106$ & -1.856 \\
\hline df_m & 33 & 33 & 33 & 33 & 33 & 33 & 33 & 33 \\
\hline Aic & 7,124 & 7,913 & 8,181 & 8,889 & 3,648 & 3,253 & 4,279 & 3,780 \\
\hline Bic & 7,358 & 8,148 & 8,420 & 9,128 & 3,882 & 3,488 & 4,517 & 4,019 \\
\hline \multicolumn{9}{|c|}{ Waist circumference z-score } \\
\hline Peer waist & 1.111 & $1.322^{* * *}$ & 1.044 & 0.993 & 1.167 & 0.722 & 1.292 & 0.707 \\
\hline $95 \% \mathrm{CI}$ & $\begin{array}{c}(0.093) \\
{[0.943} \\
1.308]\end{array}$ & $\begin{array}{c}(0.112) \\
{[1.120} \\
1.560]\end{array}$ & $\begin{array}{c}(0.079) \\
{[0.900} \\
1.210]\end{array}$ & $\begin{array}{c}(0.102) \\
{[0.812,} \\
1.215]\end{array}$ & $\begin{array}{c}(0.156) \\
{[0.898} \\
1.515]\end{array}$ & $\begin{array}{c}(0.126) \\
{[0.513} \\
1.017]\end{array}$ & $\begin{array}{c}(0.197) \\
{[0.959} \\
1.741]\end{array}$ & $\begin{array}{c}(0.175) \\
{[0.436} \\
1.148]\end{array}$ \\
\hline $\mathrm{N}$ & 7,139 & 7,427 & 8,159 & 8,390 & 7,139 & 7,427 & 8,159 & 8,390 \\
\hline $\mathrm{Ll}$ & $-3,529$ & $-3,923$ & $-4,057$ & $-4,410$ & $-1,793$ & $-1,604$ & $-2,105$ & $-1,865$ \\
\hline df_m & 33 & 33 & 33 & 33 & 33 & 33 & 33 & 33 \\
\hline Aic & 7,126 & 7,914 & 8,181 & 8,889 & 3,654 & 3,276 & 4,279 & 3,798 \\
\hline $\mathrm{Bic}$ & 7,359 & 8,149 & 8,420 & 9,128 & 3,888 & 3,511 & 4,517 & 4,037 \\
\hline \multicolumn{9}{|c|}{ Fat mass (in kg) } \\
\hline Peer fat & 1.031 & $1.065^{* *}$ & 1.015 & 1.039 & 0.977 & $0.897^{*}$ & 0.968 & $0.883^{*}$ \\
\hline $95 \%$ CI & $\begin{array}{c}(0.025) \\
{[0.983} \\
1.082]\end{array}$ & $\begin{array}{l}(0.023) \\
{[1.020} \\
1.112]\end{array}$ & $\begin{array}{c}(0.026) \\
{[0.965} \\
1.067]\end{array}$ & $\begin{array}{l}(0.033) \\
{[0.976,} \\
1.107]\end{array}$ & $\begin{array}{c}(0.039) \\
{[0.903,} \\
1.057]\end{array}$ & $\begin{array}{c}(0.043) \\
{[0.817} \\
0.985]\end{array}$ & $\begin{array}{c}(0.043) \\
{[0.887,} \\
1.057]\end{array}$ & $\begin{array}{c}(0.052) \\
{[0.787} \\
0.991]\end{array}$ \\
\hline $\mathrm{N}$ & 7,034 & 7,333 & 8,066 & 8,273 & 7,034 & 7,333 & 8,066 & 8,273 \\
\hline $\mathrm{Ll}$ & $-3,468$ & $-3,873$ & $-4,002$ & $-4,342$ & $-1,764$ & $-1,565$ & $-2,084$ & $-1,829$ \\
\hline df_m & 33 & 33 & 33 & 33 & 33 & 33 & 33 & 33 \\
\hline Aic & 7,005 & 7,814 & 8,072 & 8,752 & 3,596 & 3,197 & 4,236 & 3,725 \\
\hline $\mathrm{Bic}$ & 7,238 & 8,048 & 8,310 & 8,990 & 3,829 & 3,432 & 4,474 & 3,964 \\
\hline \multicolumn{9}{|c|}{ Percentage body fat (PBF) } \\
\hline Peer PBF & $\begin{array}{c}1.030 * * \\
(0.011)\end{array}$ & $\begin{array}{c}1.047^{* * * *} \\
(0.011)\end{array}$ & $\begin{array}{c}1.003 \\
(0.005)\end{array}$ & $\begin{array}{c}1.000 \\
(0.009)\end{array}$ & $\begin{array}{c}0.987 \\
(0.016)\end{array}$ & $\begin{array}{c}0.942 * * \\
(0.020)\end{array}$ & $\begin{array}{c}1.015 \\
(0.013)\end{array}$ & $\begin{array}{c}0.973 \\
(0.017)\end{array}$ \\
\hline $95 \%$ CI & {$[1.008$} & [1.026, & {$[0.992$} & {$[0.983$} & {$[0.956$} & [0.904, & [0.989, & {$[0.973$} \\
\hline
\end{tabular}




\begin{tabular}{lcccc|cccc} 
& $1.052]$ & $1.069]$ & $1.013]$ & $1.017]$ & $1.019]$ & $0.981]$ & $1.040]$ & $1.007]$ \\
$\mathrm{N}$ & 6,848 & 7,074 & 8,124 & 8,349 & 6,848 & 7,074 & 8,124 & 8,349 \\
$\mathrm{Ll}$ & $-3,372$ & $-3,740$ & $-4,030$ & $-4,390$ & $-1,718$ & $-1,527$ & $-2,112$ & $-1,839$ \\
df_m & 33 & 33 & 33 & 33 & 33 & 33 & 33 & 33 \\
Aic & 6,810 & 7,546 & 8,126 & 8,846 & 3,502 & 3,120 & 4,289 & 3,744 \\
Bic & 7,036 & 7,772 & 8,357 & 9,078 & 3,727 & 3,347 & 4,520 & 3,976 \\
\hline
\end{tabular}

Note: Dependent variable in the first four (last four) columns has a value equal to "1" if the parent perceives the child to be thinner (heavier) than it actually is; zero otherwise. Odd ratios are presented in the table. The analysis conducted for children aged 2-9. Regressions include child, family,parental, and socio-economic controls. Standard error in parentheses. Clustering at the setting level. ${ }^{*} \mathrm{p}<.05,{ }^{* *} \mathrm{p}<.01,{ }^{* * *} \mathrm{p}<.001$ 